\title{
A CRÍTICA E A LITERATURA BRASILEIRA: METAS, DESVIOS E HORIZONTES
}

\author{
Maria do Carmo Campos
}

RESUMO: Le texte envisage quelques aspects de la pensée critique au Brésil, caracterisée dès le début par une dualité de points de vue: d'une part, le désir d'être actualisée par rapport aux modèles littéraires et aux discours établis, d'autre part, la constituition d" un discours critique à partir du "dedans", capable d' établir la diférence et la nationalisation. Ce texte examine aussi quelque peculiarités des rapports forme littéraire - histoire et indique quelques transformations produites au XX ème siècle, c'est à dire, les déplacements evidénts de la notion, des fonctions de la littérature et de la critique, qui ont comme conséquence la production des discours de diluition de la littérature, un affaiblissement critique et une saturation interpretative. Au Brésil, l' intrincation des réseaux historiques, esthétiques et idéologiques démande des études adressées aux différences et à la compléxification actuelle du procès littéraire face aux discours critiques.

PALAVRAS-CHAVE: Literatura brasileira, crítica literária brasileira, crítica literária brasileira no século XX.

Em "O animal como linguagem", George Steiner assinala que a crítica e a história literária seriam "artes menores": "sofremos no momento uma inflação espúria da crítica, que assumiu uma espécie de papel autônomo. O interesse desperdiçado com a personalidade e as disputas dos críticos, a massa de crítica produzida sobre obras de literatura que apenas pequena parcela do público culto se preocupará em ler (...) estes são fenômenos do jornalismo e podem ser índices de uma debilitação geral. Os críticos e os historiadores de literatura escrevem sobre escrever; oferecem livros sobre livros. É insensato não ver essa deriva ontológica, quanto mais exaltar o ato de comentário sobre o de invenção: hoje há até mesmo um métier acadêmico na crítica da crítica . Não se erguem muitas estátuas dedicadas a escritores, mas, ao contrário do sombrio prognóstico de Sainte-Beuve, talvez não demorem a ser erguidas estátuas para críticos."

Em ensaio de 1979, Luiz Costa Lima aborda as funções da crítica num sécu-

Maria do Carmo Campos é professora de Literatura Brasileira do Instituto de Letras da UFRGS. 
lo que já foi considerado o "século da crítica" (p.199-207). Aponta tendências e movimentos históricos da crítica em suas funções e relações, entre as quais a oscilação entre o descritivo e o judicativo, com as conseqüentes implicações de valor estético, e a definição de um lugar face a outros discursos como o científico. Entre os aspectos analisados na prática crítica, indica a existência de normas, pressupostos e consensos, nem sempre elucidados. Estabelece distinções entre o crítico e o analista e registra o cientifícismo e a ficcionalização da crítica, esta como uma maneira de apresentar a renúncia da atividade judicativa ao mesmo tempo que se apresenta como julgamento.

\section{A HISTÓRIA E O OBJETO}

Sabe-se que , no Brasil, a constituição de um "pensamento crítico" sobre a literatura reveste de substancialidade histórica e de contributo constitutivo da nacionalidade, na medida em que se fazia necessário que a literatura aqui produzida deixasse de ser apenas objeto de olhares longínquos, curiosos de assinalar exotismos, diferenças e legitimações. A respeito, evoquem-se os nomes do alemão Friedrich Bouterwek e do suíço Simonde de Sismondi, que incluíram autores nascidos no Brasil em obras relativas à história da literatura européia, além do francês Ferdinand Denis que, em 1826, distinguiu pela primeira vez a literatura brasileira da portuguesa, tratando-a como um todo autônomo. ${ }^{1}$

Dentro de uma tendência romântica, correspondente às primeiras manifestações críticas, predominavam sistematizações cronológicas e abordagens retrospectivas ao modo de esboços, bosquejos, parnasos e florilégios, ao lado de estudos sobre a história crítica do processo de formação da literatura. Almeida Garrett, no conhecido Bosquejo da história da poesia e língua portuguesa, de 1826, já encontrava seus critérios de crítica e valoração da literatura que acontecia no Brasil: "E agora começa a literatura portuguesa a avultar e enriquecer-se com as produções dos engenhos brasileiros. Certamente é que as majestosas e novas cenas da natureza naquela vasta região deviam ter dado a seus poetas mais originalidade, mais diferentes imagens, expressões e estilo, do que neles aparece: a educação européia apagou-lhes o espírito nacional: parece que receiam de se mostrar americanos; e daí lhes vem uma afetação e impropriedade que dá quebra em suas melhores qualidades."

No bojo de um processo de colonização, o que era "brasileiro" passava a receber, como certidão de nascimento, modos de legitimação externa. Eram também adotados moldes europeus para o pensamento crítico. Tratava-se, então, de "abrasileirar", o que se efetuava em dois sentidos: traduzir em discurso brasileiro toda uma série de interpretações críticas e históricas que os "estrangeiros" vinham construindo sobre a nossa realidade sociocultural, e, na medida do possível, constituir uma visão "de dentro" sobre a literatura que aqui se ia fazendo. Entre as abordagens feitas por brasileiros, podem ser destacadas, por exemplo, as de Januário da

${ }^{1}$ Cf. Historiadores e críticos do Romantismo: a contribuição européia e a crítica literária. Seleção e apresentação de Guilhermino Cesar, 1978. 
Cunha Barbosa (Parnaso brasileiro, 1829-1831), Gonçalves de Magalhães (Ensaio sobre a história da literatura do Brasil, 1836), Joaquim Norberto de Sousa Silva (Bosquejo da história da poesia brasileira, 1841 e Estudos sobre a literatura brasileira durante o século XVII, 1843), Francisco Adolfo de Varnhagen (Florilégio da poesia brasileira,v.1, 1850) e José de Alencar (1856), além de Macedo Soares e Quintino Bocaiúva. $^{2}$

Maria Eunice Moreira salienta o papel desempenhado pela crítica tanto européia quanto brasileira no processo de desenvolvimento da literatura no Brasil:

"as questões apresentadas e discutidas pelos estudiosos marcaram profundamente a geração romântica que as conheceu, motivo pelo qual suas reflexões contribuíram para determinar a natureza e o destino das letras no Brasil.” (MOREIRA, 1991, p.14)

A autora também aponta para o entrelaçamento entre o processo de formação do patrimônio histórico brasileiro e a história do pensamento crítico, referindo os estudos posteriores de Otto Maria Carpeaux, Brito Broca, José Aderaldo Castelo e Guilhermino Cesar, que trazem à luz indicativos dos pressupostos da crítica e dos "tópicos" em torno dos quais gravitavam as discussões. O exame de tais obras permitiria acompanhar tanto sínteses crítico-históricas quanto a "curva poética brasileira em seus movimentos de apogeu e decadência" e as linhas da literatura brasileira, além das origens de um pensamento autonomista no Brasil. Ainda no âmbito do Romantismo, o enlace entre pensamento crítico e processo de formação da literatura brasileira sugere uma inclinação aglutinadora entre os enfoques dos diferentes autores, que acabam por projetar-se para questões como "constituição e desenvolvimento de um patrimônio literário original", ao lado da própria singularidade da sua evolução (Ibidem, p. $15-16)$.

As pesquisas de Guilhermino Cesar, por exemplo, voltam-se para a recuperação de textos básicos de autores europeus, como os primeiros comentários críticos sobre as manifestações literárias no Brasil: trata-se de um admirável empreendimento de coleta, tradução e crítica que veio possibilitar a leitura dessa historiografia oitocentista, "que afinal nos explicou a nós mesmos". Por outro lado, através do esforço crítico do autor, o leitor de língua portuguesa teve acesso a fontes primárias raras ou de difícil obtenção no Brasil, pela reunião de um conjunto de textos que iriam servir de alicerce a uma "crítica literária nascente". Guilhermino Cesar ressalta a contribuiçâo de Ferdinand Denis para "despertar tendências, aprofundá-las, sugerir insubmissão aos modelos da Europa, enfatizar a necessidade de nos apegarmos um pouco mais afetivamente ao país, por via de adesão (que apregoava indispensável) à temática do Indianismo" (CESAR, 1978, p. XXI). A partir de diferentes autores, percursos e peculiaridades da literatura brasileira e das visões críticas que ela ia propiciando, o autor reconhece também uma espécie de fosso cavado entre as literaturas portuguesa e brasileira, sobretudo a partir de Alencar.

Na mesma perspectiva, traz um olhar do historiador português Fidelino de

${ }^{2}$ Cf. a respeito: COUTINHO, 1974. v.1 e ZILBERMAN \& MOREIRA, 1998. 
Figueiredo voltado para uma crítica brasileira em formação: "É que a crítica brasileira tinha um pensamento crítico muito diverso do da crítica metropolitana; organizar uma tradição, como dissemos, e respirar todos os cunhos de nacionalismo diferenciador; fosse simples amor ao torrão americano, fosse malevolência contra a mãe - pátria, fosse - e era o exemplo mais feliz - vibração nova em matéria de arte." ${ }^{\prime 3}$ Apuradas as diferenças e algumas incompreensões, Guilhermino considera que a consolidação da crítica romântica brasileira muito deve aos europeus.

\section{ENFOQUES E IMPASSES}

Em texto de 1986, João Alexandre Barbosa localiza na tradição crítica brasileira uma perspectiva centrada na busca de uma diferença com relação à Europa, perspectiva em busca de uma identidade nacional. Tudo se passa como se coubesse ao intelectual empenhado ir atrás das marcas literárias, de um "reflexo" do desenvolvimento histórico, das diferenças em relação ao português: "Na verdade, por força mesmo da necessidade de marcar uma identidade em face do colonizador, sobretudo a partir da Independência, os textos que se escrevem sobre a literatura brasileira buscam identificar a correlação entre literatura e história sob o ângulo do traçado da nacionalidade, em que a primeira aparece sempre como reflexo ou ilustração da segunda."

Nesse sentido, os traços definidores da história da crítica literária brasileira teriam convergido para uma espécie de "paixão interpretativa": "desde o começo das reflexões críticas no Brasil, mesmo as menos sistemáticas, empreendidas pelos próprios criadores entre os séculos XVII e XIX, o debate converge para a busca de uma diferença com relação à Europa e, portanto, pela identidade nacional". Nessa perspectiva, as obras eram lidas como reflexo do desenvolvimento histórico, através dos temas que interessavam à interpretação da cultura pelo "intelectual empenhado".

$\mathrm{O}$ autor localiza uma continuidade do processo crítico interpretativo em relação à literatura brasileira, sem praticamente haver rupturas com a passagem da Colônia à Nação, tendo sido o historicismo romântico continuado pelos novos paradigmas da segunda metade do século XIX, o positivismo e o evolucionismo. ${ }^{5}$ Os críticos desse segundo período teriam executado um movimento circular entre a interpretação da literatura como representação da história e da história como justificativa da literatura: "Interpretar, deste modo, era, antes de mais nada, localizar na literatura os momentos de aproximação ou recuo àquilo que se afirmava como fundamento da história." 6

\footnotetext{
${ }^{3} \mathrm{O}$ texto foi publicado na História da literatura clássica . Lisboa, Portugalia, 1924. v.III. (apud CESAR, Guilhermino. Op.cit. p. LVII)

4"Paixão crítica; forma e história na crítica brasileira". Introdução a Textos críticos: Augusto Meyer. Seleção e Introdução de João Alexandre Barbosa, 1986. O mesmo texto integra o livro do autor $A$ leitura do intervalo, 1990, de onde são referidas as citações do presente trabalho.

${ }^{5}$ Em "Literatura de dois gumes", texto de 1966, Antonio Candido já observara uma continuidade no processo crítico: “ .... nossa crítica naturalista, prolongando sugestões românticas, transmitiu por vezes a idéia enganadora de que a literatura foi aqui produto do encontro de três tradições culturais: a do português, a do índio e a do africano. Ora, as influências dos dois últimos grupos só se exerceram ( e aí intensamente) no plano folclórico (...) “. In: A educação pela noite \& outros ensaios, 1987, p.165.

${ }^{6}$ Ibidem. (A leitura do intervalo) p.42.
} 
João Alexandre Barbosa salienta a necessidade de que o pensamento crítico viesse a cobrir um hiato - de certo modo já identificado por Leo Spitzer como um fosso entre a lingüística e a história - pela instauração de uma "linguagem crítica capaz de dar conta da correlação entre literatura e história sem perder os elementos de tensão que vinculam criação artística e representação." Propõe a crítica como leitura integradora da forma e da historicidade da obra literária, questionando tanto positivismos quanto individualismos exacerbados. Quanto aos métodos estéticos-sociológicos dos anos 50, de Afrânio Coutinho e de Antonio Candido, reconhece entre eles diferenças de perspectiva, formação e gosto, embora ambos coincidam quanto à preocupação com as origens e as marcas de nacionalidade.

Em "Instinto de nacionalidade", ensaio crítico de 1873, a agudeza machadiana postulava uma questão crucial quanto aos ditames crítico-interpretativos com que se enunciava até então a brasilidade. Opondo-se ao caráter absoluto e empobrecedor de certas doutrinas críticas, Machado aliviava a literatura brasileira de uma "camisa de força", a do uniforme localista, o qual, ao modo de um lacre, deveria servir para legitimá-la , pelo cenário ou pelo tema enfocado. ${ }^{7}$ No mesmo texto Machado de Assis estaria também reposicionando a problemática da passagem da história ao texto literário, passagem de recuperação igualmente complexa no inverso movimento da crítica, que vai do texto à história. ${ }^{8}$

Embora identifique um processo de continuidade, Barbosa estabelece algumas distinções entre os primeiros textos críticos escritos por brasileiros, que seguem modelos românticos e adotam tons exaltados e patrióticos, e a nossa crítica naturalista, tão "filosófica" quanto determinista, representada sobretudo por Sílvio Romero, Araripe Júnior e José Veríssimo. Se mantivermos o foco nas relações de historicidade e sua evolução historicista na crítica brasileira, poderemos atribuir a Silvio Romero o endosso de uma divisão estanque entre forma e história, por exemplo, pela separação adotada entre duas categorias, a dos padrões "estéticos" de uma obra e a de sua parte puramente narrativa, afeita ao trabalho do historiador (...). Pois justamente a fidelidade aos modelos de crítica naturalista seria responsável por uma incompreensão das relações entre literatura e história, por uma visão pejorativa do Impressionismo e por uma posição de reducionismo mimético e reflexológico. ${ }^{9}$

\footnotetext{
7“Inspirada em parte por autores franceses interessados pelo exotismo americano, a crítica literária estabeleceu então que descrever a natureza e os costumes do País, sobretudo os das raças primitivas, era a verdadeira tarefa da literatura e o critério para identificar, no passado, aqueles que tinham contribuído para criá-la." (CANDIDO, Op.cit. p. 175)

${ }^{8} \mathrm{~A}$ "paixão interpretativa" pode ser associada à defesa da objetividade do naturalismo crítico. Trata-se de duas tendências que, pela exclusão das mediações do simbólico e do imaginário, limitavam o alcance das indagações acerca do modo pelo qual a história era transfigurada em literatura. $\mathrm{O}$ naturalismo crítico, e suas correlatas visões da literatura como reflexo da história, seria revigorado no Brasil sobretudo a partir da Independência, em função mesmo da necessidade de estabelecer uma identidade em face do colonizador. (BARBOSA, Op.cit. p. 43/44).

Ibidem, p. 45 e 49

A exacerbação do impasse da crítica naturalista brasileira entre forma e história poderia ser atribuída à obra de José Veríssimo que identifica uma duplicidade fundamental entre a literatura e a história , sem que lhe tivesse sido possível "armar um esquema teórico de integração satisfatório." Apud BARBOSA, (p.46)
} 
Para o mesmo crítico, profundas metamorfoses relacionadas ao final do século XIX indiciam a necessidade de redefinição da noções de história e da forma das criações artísticas, estas visualizadas "a partir de uma espécie de interiorização cujo diagrama é dado pelo movimento mesmo de construção das estruturas do imaginário e do simbólico"; se, de um lado, questionavam-se os limites da representação pela obra, de outro, punha-se em xeque "a possibilidade da própria história enquanto mecanismo de decifração das representações".

Tem-se, por parte dos críticos, a fuga aos positivismos, a leis e sistemas e, por parte do escritor, a incorporação da reflexão sobre a própria criação, (...) Assim se o crítico, mais livre, pode aproximar-se mais do criador, este, por sua vez, pode adensar o seu texto com indagações relacionadas aos processos de representação pela literatura. A tendência crítica estaria, para João Alexandre Barbosa, na direção de reconsiderar as relações entre história e texto, valorizando o aspecto construtivo - paródia, alusão, citação, ironia, tradução, intertextualidade - sem perder de vista o movimento entre invenção e historicidade.

Se, em alguns casos, "a perda dos critérios naturalistas esvaziava a crítica do sentido da história (...) e firmava o domínio da pequena filologia, da gramatiquice, em que se tinha degradado a leitura da forma“(...), o estilhaçamento entre literatura $\mathrm{e}$ história vai persistir, representado, via de regra, pela prevalência de um sentido da história sobre a literatura, sem dar espaço à "passagem necessária e decisiva pela consciência da literatura como construção da linguagem". ${ }^{10}$

Assim, no intuito de nacionalização do pensamento crítico e de constituição de uma visão de "dentro" em relação à literatura brasileira, os paradigmas historicistas suscitavam interpretações das obras em função de uma "idéia geral do país". Imbuído de um espírito de missão nacional, Sílvio Romero foi o grande representante da crítica como interpretação da história, a qual não devia descuidar da verificação nas obras da adequação temática e da correção gramatical. Barbosa postula a importância para a crítica brasileira de repensar as relações entre estética e ideologia, através de processos de leitura capazes de abranger relações mais complexas entre forma e história, categorias a serem tratadas não como estanques, mas como interdependentes nas obras.

\section{HORIZONTES MAIS PROBLEMÁTICOS: DESLOCAMENTOS E PODERES}

Em texto também de 1986, Flora Süssekind recorta elementos relacionados à natureza e aos limites da crítica, identificando tendências, impasses e querelas,

\footnotetext{
${ }^{10}$ No mesmo ensaio, Barbosa vê o modernismo brasileiro como ampliação do questionamento das tensões entre literatura e história, quer pelo enfrentamento do que se chamou de crise da representação quer pelas reflexões críticas sobre a literatura como construção da linguagem. Apoiado em concepções de Mukarovsky, destaca na literatura a história que, através da forma, faz-se tropológica, no sentido de traduzir novos aspectos do real. (a passagem do topos, convenções já historicizadas, ao tropos).
} 
entre os quais a habilitação da função crítica entre os jornalistas e "scholars", os profissionais da área. Reconhecendo a nacionalidade como paradigma básico de avaliação da crítica brasileira e expondo o lugar da crítica em suas implicações de "autoridade", a autora distingue lugares de enunciação crítica no Brasil, alguns dos quais sob exigência rigorosa de especialização e atualização metodológica. Nos anos oitenta, o crescimento editorial teria provocado um desestímulo da reflexão crítica mais atenta, em favor de certo tratamento sobretudo comercial da literatura. Segundo a ensaísta, além do retorno da polêmica entre "scholars" e jornalistas, estariam incluídos entre os contendores os veículos ou instituições : na era da indústria cultural, as contendas não seriam mais estabelecidas entre dois ou mais intelectuais, mas entre instituições, formas de produção e reprodução, disputas entre imprensa e universidades, entre "duas máscaras da indústria da consciência" (SÜSSEKIND, 1993, p. 32).

Em texto publicado em 1996, Leyla Perrone-Moisés identifica uma certa minimização mais atual em relaçâo ao lugar da crítica que, de certo modo, passou a ser vista como "prática e instância canônica", alvo de desconfiança por parte de alguns setores. Do seu ponto de vista, o que constata é uma certa anemia crítica, enquanto diminuição dos debates $\operatorname{críticos}^{11}$, relacionada a um aumento, ao menos no Brasil, dos estudos voltados para memória e identidades culturais. Na mesma perspectiva, a autora não vê com bons olhos a ampliação diluidora das fronteiras do literário, que tende atualmente, em ajuste à vigência das teorias do pós-moderno, a confundir-se nas latitudes mais vastas dos "estudos culturais". O que restaria, então, para a literatura assumida ela mesma como crítica, transformadora, inovadora, revolucionária, utópica? Concebida apenas como cultura, a literatura não estaria arriscada a perder a sua condição de ultrapassagem dos níveis de expressão, reflexo e sintoma, condição essa capaz de dar conta da histórica função de ser ela mesma conhecimento, crítica ao real?

Face ao estágio atual das perspectivas teóricas dominantes no Brasil, a autora registra que grande parte das discussões na produção acadêmica e em congressos, tem-se concentrado em torno de cânones, com propostas de revisão baseadas não em critérios estéticos ou de gosto mas a partir de critérios extra-literários. Tais revisões do cânone teriam como objetivo a imediata inclusão dos excluídos e as exclusões correlatas seriam "exigidas em nome do politicamente correto": no enfoque assumido, tais reivindicações estariam seguidamente associadas a demandas de poder institucional ou delimitação de territórios de áreas do conhecimento (PERRONEMOISÉS, 1997, p.88).

Leyla Perrone-Moisés repropõe a questão do lugar da crítica hoje, fundamentada numa histórica associação entre um conceito mais exigente de literatura ${ }^{12} \mathrm{e}$

${ }^{11} \mathrm{~A}$ respeito, a autora refere a realização de congresso italiano centralizado no questionamento do estado atual da crítica, que apresenta sinais de desagregação e pulverização.

12“Para os modernos, a literatura não era mera depositária da tradição, conservadora de formas e idéias peremptas, ou divertimento inócuo capaz de concorrer com os CD-Rom e os vídeo-games: era forma de conhecimento, exercício da liberdade, crítica do real, mito verdadeiro, utopia, projeto, E a crítica literária, sua correlata, era diálogo, ampliação da leitura, extensão do saber e ação da obra.” Op. cit. p.88. 
a evolução do estatuto da crítica. Chama a atenção para a necessidade de rediscussão sobre o lugar do elemento estético e de revisão de certos percursos e paradigmas em vigência, estes associados muitas vezes a ditames da indústria cultural e da globalização, com posturas de assumido desprezo pelos sentidos de tradição e valor: "Deslocar-se não é voltar atrás, para manter imutáveis os valores e métodos do passado, mas reavaliálos, elaborar novos conceitos e novos discursos adequados à situação presente".

A partir do exame da matéria literária atual, Alfredo Bosi distingue uma concepção de escrita como imediação, documento bruto ou entretenimento passageiro, voltada para uma literatura de apelo, de massas, ao lado de uma outra concepção, que seria a de uma literatura hipermimética, conteudista e direcionada para um determinado público-alvo:

"Surgiram, desde pelo menos os anos 70, uma literatura e uma crítica feminista, uma literatura e uma crítica de minorias étnicas (...), uma literatura e uma crítica homossexual, uma literatura e uma crítica de adolescentes, ou de terceira idade, ou ecológica, ou terceiro mundista, ou de favelados, etc" (BOSI, 1999, p.110-111).

O ensaísta associa o pólo dessa literatura hipermediadora aos fenômenos da cultura globalizada, verificáveis em todas as artes. Avançando na análise, verifica também uma espécie de acordo entre esse tipo de literatura, que é pastiche de estilos alheios, e uma crítica para a qual

"todo o texto é uma rede de topoi ou clichês, de camadas de remissões diretas ou oblíquas, concentradas ou disseminadas, voluntárias ou não, em suma, uma crítica que desenvolve e promove uma concepção cumulativa e paroxística da intertextualidade" (Ibidem, p. 112).

Levadas tais concepções às últimas conseqüências, seria possível praticamente abstrair-se a figura do autor e perceber a escrita como "produto de uma aglutinação de subdiscursos que caberia à retórica ou à história das mentalidades classificar."

Relegada a um lugar de mal-estar, a crítica literária, dependendo do seu lugar de inscrição, hoje é submetida a mais severos julgamentos ou formas de legitimação, caso esteja voltada para valorizar os processos de criação individual e tradição cultural: é como se as relações entre indivíduo e sociedade, escrita e cultura, imaginação e memória social, já tivessem chegado a um ponto de saturação interpretativa, sem despertar maior interesse ao exame. Bosi avalia o lugar da literatura e da crítica na "era dos extremos", situadas ambas entre as imposições de mercado e a voga de certos procedimentos de desfiagem retórica. Estes, muito ao gosto de algumas instituições no Brasil, constituiriam limites quase impeditivos à construção mais ousada de um discurso crítico.

A partir de diversas circunstâncias atuais, Benedito Nunes assinala sintomas da ascensão de um novo tipo de mentalidade ou "cultura", a correspondente ao avançado domínio planetário da técnica:

"Pulsa, nesse domínio do produtivo e do rentável, que é também o da manipulação e da formalização do pensamento, (...) um ethos do lucro e do 
poder, a busca do fácil, do banal, do óbvio, com a sua mentalidade calculadora, imediatista, hedonística, espetaculosa, um tanto megalômana, pouco a pouco descentrada da reflexão, do prazer contemplativo, das inquietações intelectuais e filosóficas" (NUNES, 1999, p. 133).

É mister reconhecer uma paradoxal estranheza entre esse tipo de mentalidade e a própria literatura, afeita a outra temporalidade e a uma série de contingências, entre as quais o silêncio e a lentidão, fundantes de poesia.

Como se pode observar, algumas leituras revelam um constrangimento bastante atual em relação ao lugar e às funções da crítica literária e da própria literatura: a partir de traços contingentes como mudanças nos lugares de enunciação crítica e deslocamentos evidentes em relação à própria noção do objeto "literatura", esta vem sofrendo uma tendência a ser diluída nas águas da cultura e das ideologias. Se Flora Süssekind menciona um desestímulo à atividade da crítica, Leyla Perrone-Moisés identifica uma "anemia crítica", revestida pelas cores saudáveis do "politicamente correto", um dos mais novos objeto de canonização.

Sem avançar mais, pode-se admitir que algumas marcas que cunharam a literatura brasileira em sua história (ou formação) de algum modo têm sido representadas no pensamento crítico por aqui formulado. Entre tais marcas, evidencia-se aquilo que se pode chamar o critério de nacionalidade ou a busca do genuinamente brasileiro, com o estabelecimento de uma "diferença" que deveria identificar tanto a produção literária quanto as tendências ou paradigmas do discurso crítico. A partir da diferença , traço de identificação, ter-se-ia uma espécie de resistência cultural, complexo movimento nem sempre elucidado em suas explicitações e critérios. A diferença ou resistência sustentava-se principalmente entre a oposição às influências lusitanas e européias e a necessária legitimação da produção brasileira. Por outro lado e contraditoriamente, a literatura brasileira pautou-se, de certo modo, pelos padrões das "literaturas maiores", o que hoje seria assumido e descrito, por alguns discursos críticos, como uma relação cultural tensa e desigual entre centro e periferia.

A identificação da diferença na produção literária poética e ficcional tem sido objeto de diversos inventários e interpretações, servindo de eixo de sustentação à nacionalidade da literatura brasileira em suas particularidades. Por sua vez, a identificação de peculiaridades quanto ao pensamento crítico brasileiro passa por um certo número de questões e por um maior intrincamento histórico, estético e ideológico. Se George Steiner expressava o seu mal - estar sobre uma inflação da crítica européia nos anos sessenta deste século, temos registros de que - ao menos no Brasil - passadas algumas décadas, poderia estar ocorrendo um movimento inverso. $\mathrm{O}$ "século da crítica" estaria atravessando o seu ocaso?

A partir das colocações inventariadas por alguns nomes do pensamento crítico brasileiro, pode-se perceber que o lugar e os processos da crítica literária passam por um movimento de complexificação, historicamente justificado por intrincadas relações ideológicas, estéticas, étnicas e culturais. O lugar da crítica e de seus processos estaria hoje na direção de um descolamento de critérios de nacionalidade?

A história é um solo seguro que tem sustentado parte considerável dos dis- 
cursos sobre a literatura, vista enquanto reflexo, representação ou outro processo mimético mais elaborado. Por outro lado podem não ter a mesma evidência interpretativa certos traços de historicidade como os complexos movimentos mais atuais entre estética, cultura e ideologia que, sobretudo na progressão para o final do século XX, circundam a literatura e os discursos a ela voltados. Andar ao encalço de tais pegadas, em trilha marcada por alguns deslocamentos e muitos desvios, parece ser considerável meta para a crítica nos nossos dias. ${ }^{13}$

\section{BIBLIOGRAFIA}

BARBOSA, João Alexandre. Paixão crítica; forma e história na crítica brasileira. Introdução a Textos críticos: Augusto Meyer. Seleção e Introdução de. São Paulo, Perspectiva, Brasília, INL/ Fundação Nacional Pró-Memória, 1986.

BARBOSA, João Alexandre. A leitura do intervalo. São Paulo, Iluminuras, 1990.

BOSI, Alfredo. Os estudos literários na era dos extremos. In: Antonio Candido, pensamento e militância. Organizado por Flávio Aguiar. São Paulo, Fundação Perseu Abramo/Humanitas, FFLCH, 1999.

CAMPOS, Maria do Carmo. A matéria prismada: o Brasil de longe e de perto \& outros ensaios. Porto Alegre, Mercado Aberto/ São Paulo, EDUSP, 1999.

CANDIDO, Antonio. Literatura de dois gumes. In: A educação pela noite \& outros ensaios. São Paulo, Ática, 1987.

CESAR, Guilhermino. Historiadores e críticos do Romantismo: a contribuição européia e a crítica literária. Introdução. Rio de Janeiro, Livros Técnicos e Científicos; São Paulo, EDUSP,1978.

COUTINHO, Afrânio. Caminhos do pensamento crítico. Rio de Janeiro, Americana, Prolivro, 1974. v.1.

LIMA, Luiz Costa. Questionamento da crítica literária. Dispersa demanda. Rio de Janeiro, Francisco Alves, 1981.

MACHADO DE ASSIS. Notícia da atual literatura brasileira: Instinto de nacionalidade. Obra Completa. Organização de Afrânio Coutinho. Rio de Janeiro, Nova Aguilar, 1992. v. III.

MOREIRA, Maria Eunice. Nacionalismo literário e crítica romântica. Porto Alegre, IEL, 1991.

NUNES, Benedito. Ocaso da literatura ou falência da crítica? In: Antonio Candido, pensamento e militância. Organizado por Flávio Aguiar. São Paulo, Fundação Perseu Abramo/Humanitas, FFLCH, 1999.

PERRONE-MOISÉS, Leyla. A crítica literária hoje. Anais do V Congresso da ABRALIC. Rio de Janeiro, 1997. v.1. p.88.

SÜSSEKIND, Flora. Rodapés, tratados e ensaios. Papéis colados. Rio de Janeiro,

${ }^{3}$ Este texto corresponde à versão escrita e ampliada de comunicação apresentada ao II Fórum de Literatura Brasileira da UFRGS, realizado no Instituto Goethe, Porto Alegre, dezembro de 1998. 
UFRJ, 1993.

ZILBERMAN, Regina \& MOREIRA, Maria Eunice, orgs. O berço do cânone. Porto Alegre, Mercado Aberto, 1998. 